\title{
ALIH FUNGSI LAHAN DAN PERUBAHAN STRUKTUR OKUPASI
}

\author{
Iskandar Hamid, Idrus Hentihu, Samsia Umasugi, Abdul Latif Wabula, Said Abdurahman Assagaf, Abdi Wael, Rosita Umanailo, \\ Hamiru Hamiru, Mansyur Nawawi, Sukainap Pulhehe, Mirja Ohoibor, Riki Bugis, Edi Said Ningkeula SP, Muhammad Bula, Lutfi \\ Rumkel, Irma Magfirah, Siami Prafitriyani, Belinda Sam, Wa Malmia, Syaiful Rachman, Salma Yusuf, M Yusran Zakaria \\ Universitas Iqra Buru \\ chairulbasrun@gmail.com
}

\begin{abstract}
Abstrak
Tujuan penelitian ini mengidentifikasi sifat dari alih fungsi lahan yang menyebabkan perubahan struktur okupasi petani yang terjadi di Desa Namlea. Perkembangan proses urbanisasi di Kabupaten Buru membawa dampak tersendiri terhadap eksistensi petani dimana penelitian ini juga berupaya untuk menganalisis faktor yang mempengaruhi petani akibat proses urbanisasi tersebut. Pendekatan yang dipergunakan dalam penelitian ini menggunakan metode kualitatif dengan pendekatan deskripsi, informan yang akan diwawancarai diambil secara purposive dengan pertimbangan responden dianggap sebagai pihak-pihak yang terkait untuk mencapai tujuan penelitian. Penelitian dilakukan di Kecamatan Namlea, Kabupaten Buru dengan sampel wilayah adalah Desa Namlea. Penelitian ini menggunakan teknik pengumpulan data atau teknik yang menggunakan observasi, wawancara mendalam serta focus group discussi untuk mendapatkan data serta gambaran pokok mengenai alih fungsi lahan. Teknik analisis yang digunakan dalam penelitian adalah analisis data kualitatif mengikuti konsep yang diberikan Miles and Huberman dan Spradley. Luaran yang direncanakan berupa publikasi karya intelektual yang memiliki paten serta roadmap perencanaan alih fungsi lahan di Kabupaten Buru. Sementara untuk pencapaian TKT, penelitian ini diharapkan mampu mencapai Validasi untuk memastikan data yang diperoleh relevan dan terkait telah dilaksanakan, Pengumpulan data primer telah dilaksanakan, dan juga Dukungan data sekunder dapat melengkapi data awal yang telah diperoleh sebelumnya.
\end{abstract}

Keyword: okupasi, petani, alih fungsi lahan, perubahan

Pengembangan wilayah pedesaan dalam menunjang pembangunan daerah menjadi begitu penting dalam era desentralisasi, dimana hampir sebagian besar wilayah pedesaan di Indonesia terus dikembangkan untuk pencapaian kesejahteraan masyarakat.

Seiring dengan pencapaian masyarakat, Hadirnya Desa Namlea sebagai Ibukota Kabupaten Buru dengan sendirinya akan lahir pula berbagai permasalahan sebagai konsekuensi logis dinamika masyarakat serta perubahan menjadi masyarakat perkotaan, sehingga kondisi perubahan tersebut diharapkan mampu menjadi arah dan tujuan akhir pencapaian kesejateraan masyarakat di Kota Namlea.

Petani merupakan bagian dari struktur masyarakat Namlea yang sebelumnya telah ada, hingga pada perkembangannya menjadi ibukota kabupaten petani masih memiliki eksistensi dalam kehidupan bermasyarakat di Desa Namlea. Untuk melihat perkembangannya, petani yang berada di Desa Namlea merupakan mereka yang bekerja untuk menanami lahan pertanian dengan tanaman berumur pendek dan ada beberapa juga yang ikut menanam tanaman berumur panjang seperti kelapa dan kakao. 
Seiring dengan perkembangan wilayah, keberadaan serta eksistensi petani semakin terbatas. Peralihan lahan-lahan pertanian menjadi perumahan serta perkantoran dan juga untuk perdagangan menjadikan petani semakin kesulitan, bahkan mulai terdesak untuk keluar dan mengembangkan pertanian pada lokasi yang tentunya dengan jarak yang lebih jauh dari sebelumnya. Dengan demikian proses yang disebut dengan nama pengkotaan ini membawa dampak tersendiri bagi petani dalam pengembangan kehidupan sosial ekonominya.

Memahami proses urbanisasi sebagai proses perubahan tentunya akan melihat peran masyarakat serta lingkungan sosialnya dalam hubungan timbal balik yang saling mempengaruhi. Murat Öztürk, Beşir Topaloğlu, Andy Hilton \& Joost Jongerden (2017) dalam penelitiannya tentang Rural-Urban Mobilities in Turkey: Socio-spatial Perspectives on Migration and Return Movements, membahas pedesaan mobilitas perkotaan dan kerja kontemporer - hubungan migrasi. Dimulai dengan pengamatan berkurangnya penduduk pedesaan dengan beberapa masalah, termasuk lapangan kerja di pedesaan, proses migrasi perkotaan, pemukiman di kota, hubungan migran dengan rurality dan migrasi kontra (Öztürk, 2017).

Christian Chukwuma Opata and Odoja Asogwa (2017) mengemukakan temuan pada masyarakat Igbo tentang tanah yang dianggap sebagai sumber rezeki manusia dan sumber suci yang kekal. Mereka tidak sekedar mendewakan tanah namun leih dari itu masyarakat Igbo juga mengatur kepemilikan dan penggunaan tanah sehingga dapat menekan terjadinya alih fungsi lahan (Opata, 2107). Sementara itu, tanah bagi masyarakat Namlea telah menjadi komodifikasi dan alat pemenuhan kebutuhan dimana telah terjadi pengurangan fungsi lahan untuk pertanian yang dirubah untuk tempat tinggal dan kegiatan ekonomi.

Proses pengkotaan yang terjadi tidak serta merta hanya terjadi pada masalah lahan pertanian, perubahan alih fungsi lahan dan kepemilikan, pergeseran struktur okupasi serta perubahan sosial ekonomi petani menajadi permasalahan penting dari apa yang bisa kita lihat di Desa Namlea.

Kondisi seperti itulah yang menjadi persoalan tersendiri dalam kajian penelitian ini sehingga peneliti beranggapan perlu adanya kajian mendalam terkait konstruksi sosial ekonomi petani di Kota Namlea, sehingga pada akhirnya penelitian ini mampu melahirkan temuan maupun teori yang aplikatif terhadap persoalan yang dihadapi terkait dengan pemanfaatan lahan dan pemberdayaan petani di perkotaan.

Teori Konstruksi Sosial

Dalam aliran filsasat, gagasan konstruktivisme telah muncul sejak Socrates menemukan jiwa dalam tubuh manusia, sejak Plato menemukan akal budi dan ide. (Bertens, 1999:89). Gagasan tersebut semakin lebih konkret lagi setelah Aristoteles mengenalkan istilah, informasi, relasi, individu, subtansi, materi, esensi, dan sebagainya. la mengatakan bahwa, manusia adalah makhluk sosial, setiap pernyataan harus dibuktikan kebenarannya, bahwa kunci pengetahuan adalah fakta (Bertens, 1999:137).

Aristoteles pulalah yang telah memperkenalkan ucapannya 'Cogito ergo sum' yang berarti "saya berfikir karena itu saya ada". Kata-kata Aristoteles yang terkenal itu menjadi dasar yang kuat bagi perkembangan gagasan-gagasan konstruktivisme sampai saat ini. Pada tahun 1710, Vico dalam 'De Antiquissima Italorum Sapientia', mengungkapkan filsafatnya dengan berkata 'Tuhan adalah pencipta alam semesta dan manusia adalah tuan dari ciptaan'. Dia menjelaskan bahwa 'mengetahui' berarti 'mengetahui bagaimana membuat sesuatu 'ini berarti seseorang itu baru mengetahui sesuatu jika ia menjelaskan unsur-unsur apa yang membangun sesuatu itu. Menurut Vico bahwa hanya Tuhan sajalah 
yang dapat mengerti alam raya ini karena hanya dia yang tahu bagaimana membuatnya dan dari apa ia membuatnya, sementara itu orang hanya dapat mengetahui sesuatu yang telah dikonstruksikannya (Suparno, 1997:24).

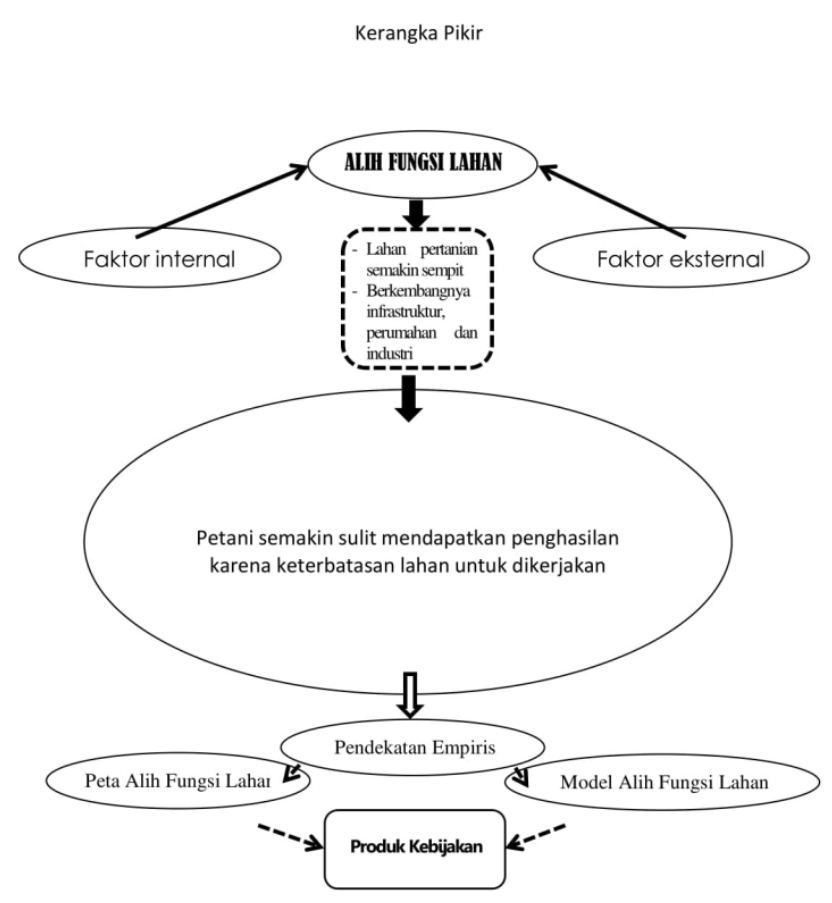

Konstruksi sosial merupakan sebuah teori sosiologi kontemporer yang dicetuskan oleh Peter L.Berger dan Thomas Luckman. Dalam menjelaskan paradigma konstruktivis, realitas sosial merupakan konstruksi sosial yang diciptakan oleh individu. Individu adalah manusia yg bebas yang melakukan hubungan antara manusia yang satu dengan yang lain. Individu menjadi penentu dalam dunia sosial yang dikonstruksi berdasarkan kehendaknya. Individu bukanlah korban fakta sosial, namun sebagai media produksi sekaligus reproduksi yang kreatif dalam mengkonstruksi dunia sosialnya (Basrowi dan Sukidin, 2002 : 194).

Pertama, mendefinisikan kembali pengertian "kenyataan" dan "pengetahuan" dalam konteks sosial. Teori sosiologi harus mampu menjelaskan bahwa kehidupan masyarakat itu dikonstruksi secara terusmenerus. Gejala-gejala sosial sehari-hari masyarakat selalu berproses, yang ditemukan dalam pengalaman bermasyarakat. Oleh karena itu, pusat perhatian masyarakat terarah pada bentuk-bentuk penghayatan (Erlebniss) kehidupan masyarakat secara menyeluruh dengan segala aspek (kognitif, psikomotoris, emosional dan intuitif). Dengan kata lain, kenyataan sosial itu tersirat dalam pergaulan sosial, yang diungkapkan secara sosial termanifestasikan dalam tindakan. Kenyataan sosial semacam ini ditemukan dalam pengalaman intersubyektif (intersubjektivitas). Melalui intersubyektifitas dapat dijelaskan bagaimana kehidupan masyarakat tertentu dibentuk secara terus-menerus. Konsep intersubyektifitas menunjuk pada dimensi struktur kesadaran umum ke kesadaran individual dalam suatu kelompok khusus yang sedang saling berintegrasi dan berinteraksi.

Kedua,menemukan metodologi yang tepat untuk meneliti pengalaman intersubyektifitas dalam kerangka mengkonstruksi realitas. Dalam hal ini, memang perlu ada kesadaran bahwa apa yang dinamakan masyarakat pasti terbangun dari dimensi obyektif sekaligus dimensi subyektif sebab masyarakat itu sendiri sesungguhnya buatan kultural dari masyarakat (yang di dalamnya terdapat hubungan intersubyektifitas) dan manusia adalah sekaligus pencipta dunianya sendiri. Oleh karena itu, dalam observasi gejala-gejala sosial itu perlu diseleksi, dengan mencurahkan perhatian pada aspek 
perkembangan, perubahan dan tindakan sosial. Dengan cara seperti itu, kita dapat memahami tatanan sosial atau orde sosial yang diciptakan sendiri oleh masyarakat dan yang dipelihara dalam pergaulan sehari-hari.

Ketiga, memilih logika yang tepat dan sesuai. Peneliti perlu menentukan logika mana yang perlu diterapkan dalam usaha memahami kenyataan sosial yang mempunyai ciri khas yang bersifat plural, relatif dan dinamis. Yang menjadi persoalan bagi Berger adalah logika seperti apakah yang perlu dikuasai agar interpretasi sosiologi itu relevan dengan struktur kesadaran umum itu? Sosiologi pengetahuan harus menekuni segala sesuatu yang dianggap sebagai "pengetahuan" dalam masyarakat (Demartoto, 2013).

\section{Referensi}

Alam,A. F. M. Ashraful et.al. 2016. Rural settlements dynamics and the prospects of densification strategy in rural Bangladesh. SpringerPlus 5:254. DOI 10.1186/s40064-016-1883-4.

Asfaw, Amogne. et.al. 2017. Determinants of non-farm livelihood diversification: evidence from rainfed-dependent smallholder farmers in northcentral Ethiopia (Woleka sub-basin). Development Studies Research. VOL. 4, NO. 1, 22-36.

Basrowi dan Sukidin. 2002. Metode Penelitian Perspektif Mikro: Grounded theory, Fenomenologi, Etnometodologi, Etnografi, Dramaturgi, Interaksi Simbolik, Hermeneutik, Konstruksi Sosial, Analisis Wacana, dan Metodologi Refleksi, Surabaya: Insan Cendekia.

Berger Peter dan Luckman, Thomas. 1990 "Tafsiran Sosial Atas Kenyataan Risalah Tentang Sosiologi Pengetahuan". LP3ES, Jakarta.

Bertens, Kees. 2002. Filsafat Barat Kontemporer. Pustaka Kanisius. Yogyakarta.

Corrado Diamantini. 2016. Peri-urban agriculture as key driver to sustainability. A planning project in an Alpine city. City, Territory and Architecture. DOI 10.1186/s40410-016-0044-y.

Demartoto, Argyo. 2013. Teori Konstruksi Sosial dari Peter L Berger dan Thomas Luckman. http://argyo.staff.uns.ac.id/. Diakses tanggal 22 September 2018.

Denzin, K. Norman, Yvonna S. Lincoln. 2009. Handbook of Qualitative Research. Yogyakarta. Pustaka Pelajar.

Hamid, I. (2010). Identifikasi gulma pada areal pertanaman cengkeh Eugenia aromatica) di Desa Nalbessy Kecamatan Leksula Kabupaten Buru Selatan. Agrikan: Jurnal Agribisnis Perikanan, 3(1), 62-71.

Handewi, P.S. Rachman dan Mewa Ariani. 2014. Ketahanan Pangan : Konsep, Pengukuran dan Strategi. FAE. Vol 20. No.1. Hal 54-59

Hentihu, Idrus (2007) Analisisi Pemasaran Tanaman Nilam (Pogostemon cablin Benth)( Studi Kasus Desa Pamotan Kecamatan Dampit Kabupaten Malang ). Other thesis, University of Muhammadiyah Malang. diakses tanggal 15 Agustus 2018.

Lemus, Yadira Méndez \& Antonio Vieyra. 2017. How social capital enables or restricts the livelihoods of poor peri-urban farmers in Mexico, Development in Practice, 27:3, 301-315, DOI: 10.1080/09614524.2017.1296109.

Magfirah, I. (2017). Efektivitas Model Pembelajaran Discovery dengan Setting Kooperatif Ditinjau dari Kemampuan Analogi dan Generalisasi Matematis Siswa Kelas VII MTs Al-Fakhriyah Makassar (Doctoral dissertation, Universitas Negeri Makassar).

Magfirah, I., Rahman, U., \& Sulasteri, S. (2015). Pengaruh Konsep Diri Dan Kebiasaan Belajar Terhadap Hasil Belajar Matematika Siswa Kelas Viii Smp Negeri 6 Bontomatene Kepulauan Selayar. MaPan: Jurnal Matematika dan Pembelajaran, 3(1), 103116.

Ningkeula, E. S. (2015). Analisis karakteristik metereologi dan morfologis DAS Wai Samal Kecamatan Seram Utara Timur Kobi Kabupaten Maluku Tengah. Agrikan: Jurnal Agribisnis Perikanan, 8(2), 81-91.

Ningkeula, E. S. (2016). Analisis karakteristik morfometri dan hidrologi sebagai ciri karakteristik biogeofisik DAS Wai Samal Kecamatan Seram Utara Timur Kobi Kabupaten Maluku Tengah. Agrikan: Jurnal Agribisnis Perikanan, 9(2), 76-86.

Opata, Christian Chukwuma and Odoja Asogwa. 2017. Rituals and Land Use: The Heritage of a Nigerian Society: SAGE Open April-June 2017: 1-11, DOI: 10.1177/2158244016689129.

Öztürk, Murat et.al. 2017. Rural-Urban Mobilities in Turkey: Socio-spatial Perspectives on Migration and Return Movements, Journal of Balkan and Near Eastern Studies, DOI: 10.1080/19448953.2018.1406696. 
Pulhehe, S. (2001). Tinjauan PP Nomor 10 Tahun 1983 Menurut Hukum Islam (Perkawinan-Perceraian) (Doctoral dissertation, Universitas Airlangga).

Resnick, Danielle. et.al. 2018. The Kaleidoscope Model of policy change: Applications to food security policy in Zambia. World Development, 106; 101-120.

Roy, Animesh. 2016. Land acquisition and rural transformation: A case study from West Bengal. Chinese Sociological Dialogue, Vol. 1(1) 32-47. DOI: 10.1177/2397200916663010.

Sugiyono. 2012. Metode Penelitian Kualitatif, Kualitatif dan R \& D. Bandung. Alfabeta.

Suparno. 1997. "Filsafat Konstruktivisme dalam Pendidikan". Yogyakarta: Kanisius.

Umanailo, M Chairul Basrun . 2017. "Marginalisasi Buruh Tani Akibat Alih Fungsi Lahan.” OSF. December 11. doi:10.17605/OSF.IO/9CZK2.

Umanailo, M Chairul Basrun. (2019). Strategi Bertahan Hidup Petani Padi Gogo Di Pulau Buru Survival Strategies Of The Upland Rice Farmers In Buru Island. Jurnal Ekonomi Pertanian dan Agribisnis, 3 (1);50-58.

Umanailo, M Chairul Basrun. 2017. “Kajian dan Analisis Sosiologi.” OSF. December 11. doi:10.17605/OSF.IO/PV24F.

Umanailo, M Chairul Basrun. 2017. "Keterlekatan Petani Dan Transaksi Non Tunai Dalam Pemasaran Hasil Pertanian." OSF. November 4. doi:10.17605/OSF.IO/6HS5E.

Umanailo, M Chairul Basrun. 2017. “Masyarakat Buru Dalam Perspektif Kontemporer.” OSF. December 10. doi:10.17605/OSF.IO/KZGX3.

Umanailo, M Chairul Basrun. 2017. “Penciptaan Sumberdaya Manusia Yang Berkarakter." OSF. October 31. doi:10.17605/OSF.IO/VP2AD.

Umanailo, M Chairul Basrun. 2018. "Ilmu Sosial Budaya Dasar." OSF. March 17. doi:10.17605/OSF.IO/4HPWC.

Umanailo, M. Chairul Basrun et al. 2018. Moral Economics and Survival Strategies of the Upland Rice Farmers. International Journal of Innovative Science and Research Technology (IJISRT). 3 (7); 616-622.

Umanailo, Rosita (2009) Studi Tentang Struktur Dan Komposisi Hutan Pantai Sendang Biru Malang Selatan. Other Thesis, University Of Muhammadiyah Malang. http://eprints.umm.ac.id/11153/ diakses tanggal 15 Agustus 2018.

Umanailo, Rosita (2013) Implementasi Kebijakan Perum Perhutani Dalam Pengelolaan Sumberdaya Hutan Bersama Masyarakat Sekitar Hutan (Studi Di Wilayah Perum Perhutani Kph Malang). Master thesis, University of Muhammadiyah Malang. http://eprints.umm.ac.id/30546/ diakses tanggal 15 Agustus 2018.

Uniqbu, Pusat S P d P, Abdul L Wabula, Said A Assagaf, Abdi Wael, Idrus Hentihu, Rosita Umanailo, Hamiru, et al. 2018. “Gerakan Bupolo Magrib Mengaji Sebagai Media Aktualisasi Pruralisme." OSF. October 6. doi:10.17605/OSF.IO/FDZ3N.

Uniqbu, Pusat S P d P, Belinda Sam, Lutfi Rumkel, Abdi Wael, Idrus Hentihu, Rosita Umanailo, Hamiru, et al. 2018. "Feminisme Perempuan Adat Di Pulau Buru." OSF. October 7. osf.io/j9r8u.

Uniqbu, Pusat S P d P, Edi S Ningkeula, Belinda Sam, Lutfi Rumkel, Abdi Wael, Idrus Hentihu, Samsia Umasugi, et al. 2018. "Daya Dukung Kawasan Pedesaan Di Pesisir Barat Pulau Buru Untuk Pengembangan Wisata Bahari." OSF. October 7. doi:10.17605/OSF.IO/MYFS6.

Uniqbu, Pusat S P d P, M Y Zakaria, Salma Yusuf, Syaiful Rachman, Wa Malmia, Belinda Sam, Abdul L Wabula, et al. 2018. "Gerakan Buru Membaca Sebagai Media Pembelajaran Masyarakat Di Kabupaten Buru." OSF. October 7. doi:10.17605/OSF.IO/NECH5.

Vandercasteelen, Joachim. et. al. 2018. Big cities, small towns, and poor farmers: Evidence from Ethiopia. World Development, $106 ; 393-406$.

Zakaria, M. Y. (2017). Karakteristik Penyelesaian Masalah Matematika ditinjau dari Kecenderungan Kepribadian Pada Siswa kelas X SMA Negeri 16 Makassar (Doctoral dissertation, Pascasarjana).

Zhang, Wei. et. al. 2018. Farmers' perceptions of crop pest severity in Nigeria are associated with landscape, agronomic and socio-economic factors. Agriculture, Ecosystems and Environment, 259; 159-167 